\author{
ИННОВАЦИОННОЕ ОБЕСПЕЧЕНИЕ КАЧЕСТВА УПРАВЛЕНИЯ \\ КЛИЕНТСКОЙ СЛУЖБОЙ НА ОСНОВЕ БЕРЕЖЛИВОГО ПРОИЗВОДСТВА \\ М.В. Карасева, Е.В. Трошкова
}

\begin{abstract}
Карасёва Мария Владимировна, магистрант кафедры управления качеством, стандартизации и документационного обеспечения управления, Сибирский государственный университет науки и технологий имени академика М.Ф. Решетнева, Красноярск, Россия. E-mail: karasevamaria1990@mail.ru
\end{abstract}

Трошкова Екатерина Викторовна, кандидат экономических наук, доцент кафедры управления качеством, стандартизации и документационного обеспечения управления, Сибирский государственный университет науки и технологий имени академика М.Ф. Решетнева, Красноярск, Россия. РИНЦ SPIN-код: 3378-1741 E-mail: egorova0377@mail.ru

\begin{abstract}
Аннотация. Поиск подходов совершенствования системы сочиального обеспечения является первостепенной задачей государственного управления. Процесс оказания государственных услуг в системе социального обеспечения реализуется клиентской службой. Ориентация на потребителя - главное направление развития клиентской службы. Существующие подходы по обеспечению качества управления клиентской службой в условиях многозадачности сложно реализуемы. Необходим инновационный подход, который позволит объединить зарубежный и российский опыт, накопленный в различных сферах деятельности, и применить его к системе сочиального обеспечения. Отсутствие методик по измерению экономического эффекта от внедрения бережливого производства в деятельность органов государственного управления подчеркивает актуальность настоящей работы. Целью настоящей работы является разработка инновачионных подходов для обеспечения качества управления клиентской службь в системе сочиального обеспечения на основе применения стандартов по бережливому производству. В качестве методологии были применены отдельные элементы системы менеджмента бережливого производства - принципь; подходы $\kappa$ распределению организационных ролей; подходь $к$ управлению операционной деятельностью и вспомогательными ресурсами; подходы к оценке качества функционирования и улучшения деятельности клиентской службы. В работе использованы следуюшие инструменты бережливого производства - картирование потока создания иенностей; стандартизация оказания услуг/операций клиентской службой; визуализация информации для потребителей; применение система $5 \mathrm{~S}$; руководство по системе подготовки персонала. Область применения
\end{abstract}


инновачионных подходов может быть распространена на другие территориальные органов социального обеспечения РФ, а также прочие службы системы государственного управления. Основные результаты: найдень резервы для сокращения трудозатрат специалистов клиентской службы и снижения потерь при операционной деятельности; определень возможности для повышения уровня доступности и информированности граждан, повышения качества их обслуживания и компетентности персонала клиентских служб в области бережливого производства; определены требования $к$ компетентности специалистов клиентской службы, способных оказывать весь спектр услуг в зависимости от жизненной ситуации гражданина.

Ключевые слова: бережливое производство, визуализачия, инновачионное обеспечение, картирование потока создания ценностей, качество управления, клиентская служба, операционная деятельность, система $5 \mathrm{~S}$, стандартизация оказания услуг, экономический эффект.

\title{
INNOVATIVE MANAGEMENT QUALITY ASSURANCE CUSTOMER SERVICE BASED ON LEAN PRODUCTION
}

\author{
Maria V. Karaseva, \\ Master student of the Department of Quality Management, \\ Standardization and management documentation, Reshetnev Siberian State \\ University of Science and Technology, Krasnoyarsk, Russian Federation. \\ E-mail: karasevamaria1990@mail.ru \\ Ekaterina V. Troshkova, \\ $\mathrm{PhD}$ in Economics, Associate Professor, Department of Quality \\ Management, Standardization and management documentation, \\ Reshetnev Siberian State University of Science and \\ Technology, Krasnoyarsk, Russian Federation. \\ E-mail: egorova0377@mail.ru
}

\begin{abstract}
The search for approaches to improving the social security system is the primary task of public administration. The process of providing public services in the social security system is implemented by customer service. Customer focus is the main direction of customer service development. Existing approaches to ensure the quality of customer service management in multitasking are difficult to implement. An innovative approach is needed that will allow combining foreign and Russian experience gained in various fields of activity and applying it to the social security system. The lack of methods for measuring the economic effect of the introduction of lean production in the activities of government bodies underlines the relevance of this work. The aim of this work is to develop innovative approaches to ensure the quality of customer service management in the social security system based on the application of lean manufacturing standards. As a methodology, individual elements of the lean manufacturing management system were applied - principles; approaches to the distribution of organizational roles; approaches to managing operations and support resources; approaches to assess the quality of functioning and improve the performance of
\end{abstract}


customer service. The following lean manufacturing tools were used in the work - mapping the stream of creating value; standardization of the provision of services / operations by customer service; visualization of information for consumers; $5 \mathrm{~s}$ application system; guidance on the training system. The scope of innovative approaches can be extended to other territorial social security bodies of the Russian Federation, as well as other services of the public administration system. Key results: reserves were found to reduce the labor costs of customer service specialists and reduce losses during operations; identified opportunities to increase the level of accessibility and awareness of citizens, improve the quality of their services and the competence of customer service personnel in the field of lean manufacturing; the requirements for the competence of customer service specialists who are able to provide a full range of services depending on the life situation of a citizen are defined.

Keywords: lean manufacturing, visualization, innovative support, mapping of the stream of creating value, quality of management, customer service, operational activities, $5 \mathrm{~S}$ system, standardization of service delivery, economic effect.

\section{Введение.}

Необходимость совершенствования системы государственного управления отражена в Указе Президента РФ от 7 мая 2012 г. № 601 «Об основных направлениях совершенствования» ${ }^{1}$. Поиск подходов совершенствования системы социального обеспечения является первостепенной задачей государственного управления. Процесс оказания государственных услуг в системе социального обеспечения реализуется клиентской службой. Ориентация на потребителя - главное направление развития клиентской службы. Актуальные задачи, связанные с повышением удовлетворенности потребителей клиентской службы, в том числе за счет сокращения времени ожидания в очереди при обращении граждан требует поиска резервов сокращения трудозатрат и управленческих решений по повышению производительности труда. Цифровизация государственного управления и задачи, связанные с увеличением объема оказанных государственных услуг посредством электронных сервисов, в том числе для создания прозрачной системы для мониторинга результативности, наглядно демонстрирует изменчивость внешней среды и также требует создание гибкой системы управления. Данные, опубликованные в сборнике «Индикаторы цифровой экономики» ${ }^{2}$ в категории «получение населением государственных и муниципальных услуг в электронной форме» за три года с 2015 до 2018 увеличился с 31\% до 75\%. Существующие подходы по обеспечению качества управления клиентской службой в условиях многозадачности сложно реализуемы. При этом достичь поставленных целей нужно с минимальными затратами, в том числе трудовыми и материально техническими. Необходим инновационный подход, который позволит объединить зарубежный и российский опыт, накопленный в различных сферах деятельности, и применить его к системе социального обеспечения. Стандарты на системы менеджмента являются успешным опытом повышения эффективности деятельности, применение которого подтверждено научными публикациями. Несмотря на наличие примеров повышения эффективности деятельности сегодня остается низкая степень формализуемости результатов внедрения системы менеджмента бережливого производства, а отсутствие методик по измерению полученного

\footnotetext{
1 Указ Президента РФ от 7 мая 2012 г. № 601 «Об основных направлениях совершенствования»//Собрание законодательства Российской Федерации.-7 мая 2012 г. - № 19 - ст. 2338.

${ }^{2}$ Индикаторы цифровой экономики: 2019: статистический сборник / Г. И. Абдрахманова, К. О. Вишневский, Л. М. Гохберг и др.; Нац. исслед. ун-т «Высшая школа экономики». - М.: НИУ ВШЭ, 2019. - 248 с.
} 
экономического эффекта в деятельности органов государственного управления в долгосрочной перспективе подчеркивает актуальность настоящей работы. Целью написания статьи является разработка подходов для инновационного обеспечения качества управления клиентской службы в системе социального обеспечения на основе применения стандартов по бережливому производству.

\section{Методология исследования.}

В качестве методологии были применены требования ГОСТ Р 56404-2015 «Бережливое производство. Требования к системам менеджмента» и его элементы - принципы бережливого производства, подходы к формированию организационной среды, распределению организационных ролей, управлению операционной деятельностью и вспомогательными ресурсами, оценке качества функционирования и улучшению. В работе использованы такие инструменты бережливого производства как картирование потока создания ценностей; стандартизация оказания услуг/операций клиентской службой; визуализация информации для потребителей; применение система $5 \mathrm{~S}$; руководство по системе подготовки персонала. Также при написании работы применялись методы анализа научной литературы по теме исследования, графические методы для представления статистической информации, математические методы для расчета показателей и экономического эффекта.

\section{Авторские концептуальные подходы к решению проблемы.}

Сущность инновационного обеспечения управления качеством услуги организации состоит в формировании научных заделов (банка новаций) для продукции/услуги по всем стадиях жизненного цикла. Работы по изучению инновационного обеспечения качества продукции встречаются начиная с 1985 г. W. N. Hosley [25] предложил методы, необходимые для осуществления предупреждающих действий по обеспечению качества проекта. Т.Р. Мкртчян [14] отмечает, что инновационное обеспечение качества продукции и процессов в значительной мере определяет «выживаемость организации в условиях рынка, рост эффективности производства, экономию всех видов ресурсов, используемых на предприятии», и дает возможность «контролировать качество в любой точке процесса, хеджируя все возможные риски возникновения несоответствия». Р.В. Жариков в своих работах $[7,8]$ представил историю развития инновационного обеспечения управления качеством продукции в машиностроении и разработал модель процессов инновационного обеспечения управления качеством машиностроительной продукции, где связал сетевую модель бизнеса с возможностью создавать, внедрять и использовать инновации в производстве продукции машиностроения. Автор отметил неограниченные возможности обмена опытом, использование передовой практики, инициирование новых идей и совместных проектов в сложной социально-экономической системе. Герасимова Г.А., Жариков В.Д. [2] отмечают повышение производительности труда, повышение технического уровня и качества продукции, снижение затрат на качество при внедрении инновационного обеспечения управления качеством, благодаря созданию научных заделов (банка новаций). С.В. Артюхина, Г.В. Панкина, А.И. Соляник [1] предложили иерархическую модель оценки деятельности в рамках совершенствования механизмов инновационного обеспечения управления качеством в региональных системах среднего профессионального образования. Методам и алгоритмам инновационного обеспечения управления качеством посвящены работы К.В. Матвеевой [13], А.Н. Шулешко [23] и М.В. Ястребовой [24]. 
В монографии «Система менеджмента качества: инновационный проект» рассмотрены внутренние препятствия, мешающие развитию организации. Создания продуктивной среды, позволяющей добиться конкурентных преимуществ за счет предоставления продукции (услуги), отвечающей требованиям потребителей и применимым законодательным и нормативноправовым требованиям позволяет повысить результативность процессов и эффективность организации, отмечает В.В. Левшина [9]. Результаты научных исследований Саликова Ю.А. и Каблашовой И.В. [18] подтверждают вывод, что внедрение системы менеджмента качества организации - инновация в области общего управления организацией, которая создает среду для развития творчества сотрудников и их активного вовлечения во все области её деятельности. Следует отметить, что большинство моделей сформированы на базе подходов к управлению сложными социально-экономическими системами, к которой и относится система социального обеспечения.

Применение инновационных подходов для решения задач по совершенствованию системы менеджмента социального обеспечения требует обобщения существующих положений и с учетом специфики реализуемых процессов. Поэтому нами сформулировано определение понятию «инновационное обеспечение» с точки зрения процессного подхода. Процесс инновационного обеспечения понимается как совокупность обеспечивающих процессов, генератором реализации которых выступает новое мышление по бережливости и новые ценности, отражающие принципы бережливого производства. Результатом инновационного обеспечение является создание внутренней среды, которая позволит повышать вовлеченность персонала и удовлетворенность потребителей продукцией/услугами и при этом демонстрировать повышение эффективности организации, получая дополнительные преимущества в результате постоянного улучшения процессов. Графически модель процесса «Инновационное обеспечение», построенного в соответствии с процессным подходом ГОСТ Р ИСО 9001-2015³ представлена на рис. 1.

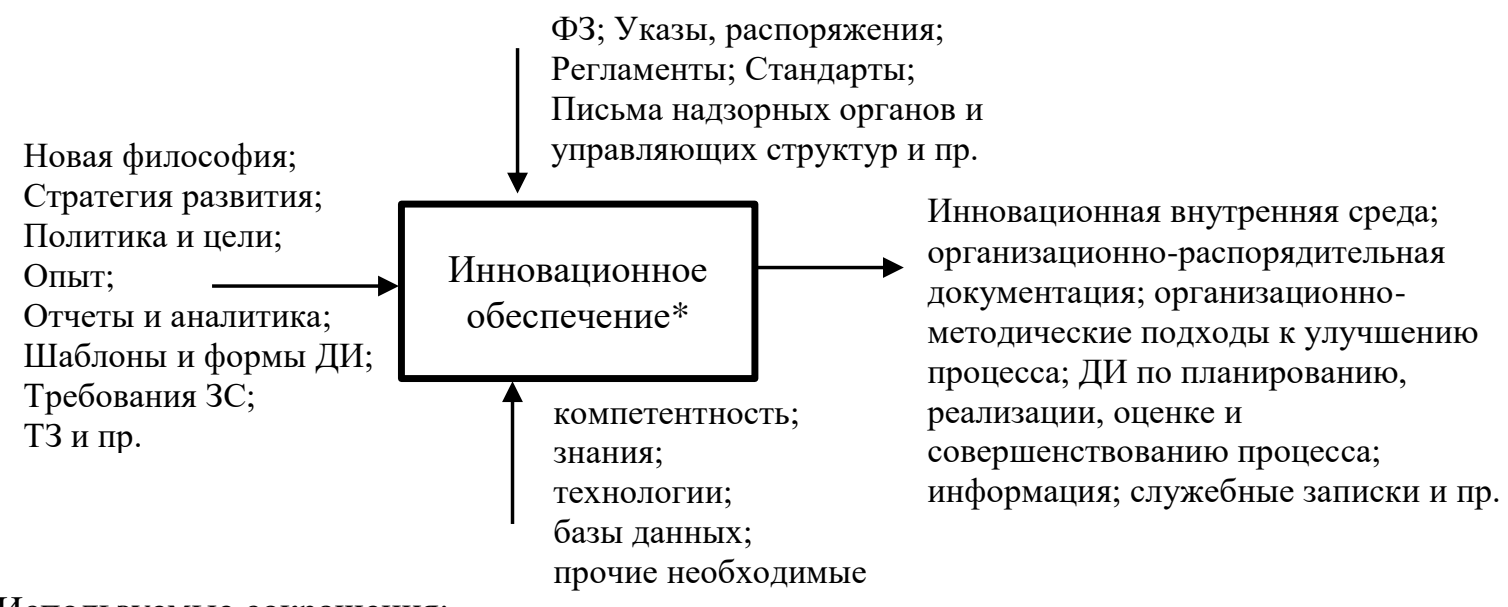

Используемые сокращения:

БП - бережливое производство;

ДИ - документированная

информация;

ЗС - заинтересованные стороны;

Т3 - техническое задание

3 ГОСТ Р ИСО 9001-2015 «Система менеджмента качества. Требования».-М.: Издательство «Стандартинформ», 2015.-23 c. 


\section{Рисунок - Модель процесса «Инновационное обеспечение»}

* включает обеспечивающие процессы системы менеджмента: управление инфраструктурой; человеческими ресурсами; средой для функционирования процессов; ресурсами для мониторинга и измерения; знаниями; информационно-документационным обеспечением; информационными технологиями; финансами и пр.

Нами уточнено понятие «качество управления клиентской службой» с точки зрения ожидания потребителей. Под качеством управления клиентской службой мы будем понимать такую организацию процесса предоставления государственных услуг, при которой обеспечивается достижение намеченных результатов наиболее эффективным способом, организована среда и выделяются достаточное количество ресурсов для надлежащего исполнения трудовых обязанностей (отсутствие нарушений в деятельности специалиста, высокая удовлетворенность граждан качеством предоставления государственных услуг, отсутствие жалоб) и отсутствуют потери (временные, финансовые, материально-технические). Таким образом, применительно к клиентской службе под инновационным обеспечением качества управления мы будем понимать процесс формирования инновационной среды для предоставления государственных услуг наиболее эффективным способом. В статье «Оценка менеджмента качества системы социального обеспечения [15] рассмотрены целевые показатели деятельности клиентской службы, в том числе: уровень удовлетворенности граждан, доступ к получению государственных услуг по принципу «одного окна», получение государственных услуг в электронном виде, время ожидания в очереди не более 15 минут. Также в указанной работе отмечено, что удовлетворенность граждан зависит не только от режима работы и ожидания в очереди, но и от качества обслуживания, наличия комфортных условий в зале ожидания и возможности получить дополнительную консультацию.

Наличие национального проекта «Производительность труда и поддержка занятости» ${ }^{4}$, межрегионального форума бережливых технологий ${ }^{5}$ и рост количества публикаций по применению инструментов бережливого производства в той или иной отрасли, позволяют говорить об актуальности данной концепции. Следует отметить монографию Д.А. Маркова [12], где уже в названии «Бережливое и быстрореагирующее производство» заложена концепция гибкого инновационного обеспечения, позволяющая реагировать на запросы и изменения внешней среды. Лапидус В., Олухов А. 10, 11] рассматривают влияние бережливого производства на развитие производственных систем и обосновывают необходимость применения данной концепции для повышения эффективности предприятий и экономики страны в целом. И.И. Чайка [22] в своей статье отмечает, что система менеджмента бережливого производства уже действует, имеет первые результаты и демонстрирует свою жизнеспособность.

Последние два года увеличилось количество публикаций, касающихся внедрения бережливого производства в сфере оказания государственных и муниципальных услуг. Согласно оценкам Дмитриева М.Э., Золотаревой А.Б., Крапиля В.Б. [3-5] внедрение бережливых

\footnotetext{
${ }^{4}$ Национальный проект «Производительность труда и поддержка занятости».-Текст: электронный [сайт].-Режим доступа: URL.: https://производительность.pф/ru/about-fcc/generalinfo/ (дата обращения: 30.03.2020)

5 Бережливая технология 2.0 Энергия действий.- Текст: электронный [сайт].-Режим доступа: URL.: https://leanforum31.ru/\#rec154355258 (дата обращения: 02.04.2020).
} 
технологий позволит оптимизировать процессы и повысить его эффективность примерно на $30 \%$ путем устранения избыточных действий, документов и бизнес-ролей. Царенко А.С. отмечает, что на федеральном уровне в государственном управлении РФ скорее идет оптимизации процессов (например, в рамках реализации технологий «электронного правительства»), а не бережливых технологий, которые не требуют больших капиталовложений и позволяют раскрыть потенциал персонала при оптимизации рабочих процессов [20, с. 101]. Автором собраны примеры, подтверждающие их эффективность: возможность выполнять больший объем работы, не привлекая дополнительные трудовые ресурсы; снижать стоимость предоставления государственных услуг, повышать удовлетворенность клиента, сокращать время, затрачиваемое на оказание услуги. Причем, как отмечает автор - «всё это альтернативные подходы, не зависящие от дорогостоящих ИТ-решений». Таким образом, задача повышения качества государственных и муниципальных услуг является не только теоретически важной, но и практически востребованной в современных условиях реформирования системы государственного и муниципального управления. В работах Царенко А.С. [20, 21] бережливое производство применяет в региональной и муниципальной деятельности и получает «бережливый регион», «бережливую поликлинику», «бережливый город», «бережливое правительство». Едаменко Е.А., Панибратеца Е.Ю., Чукавова Е.С. [6] используют термин «бережливое государство» (Lean Goverment), подчеркивая универсальность методов и инструментов бережливого производства. Савицкой И.М., Горбаневым С.В., Андреевой И.В. [17] обосновано влияние концепция «бережливого производства» на качество функционирования многофункционального центра.

Поэтому для формирования инновационной среды в рамках данной работы нами выбрана философия бережливого производства как наиболее актуальная в условиях решаемых задач по повышению эффективности деятельности. Стандартизация и механизм, обеспечивающий упреждающее развитие по отношению к динамике потребностей, позволяет создавать продуктивную инновационную среду. Мак-Кинли ${ }^{6}$ указывал на важность наличия стандартов, которые являются для руководителей «дорожной картой» при внедрении требований. Он отмечает, что «прелесть стандарта ISO заключается в том, что для небольшой компании, которая не может позволить себе нанять крупную консалтинговую фирму для выполнения работы, они могут вместо этого купить этот стандарт, применить стратегии, и это поможет сократить ресурсы». Формирование проактивного мышления и поведения для выработки новых навыков, полезных современной организации, умение формулировать проблемы и брать не себя ответственность за их решение, все это является сегодня актуальной задачей, отмечает Т.В. Плетнева [22]. Д. Сиббет [23] знакомит с актуальными инструментами визуализации и способами их применения на практике. Визуализация, по мнению автора, позволяет «радикально улучшить стиль руководства, помочь провести непопулярные, но необходимые перемены, сплотить коллектив, вдохновить сотрудников, изменить отношение к делу и повысить производительность».

Основные положения и принципы бережливого производства, на которых строится концепция системы менеджмента отражает ГОСТ Р 56020-2014 «Бережливое производство. Основные положения и словарь ${ }^{7}$ Поставленные задачи по совершенствованию государственного

\footnotetext{
6 Lockett, K. Building success through people. ISO focus, 2020.- pp. $43-49 . \quad$ - $\quad$ S. $46 . \quad$ URL.: https://www.iso.org/files/live/sites/isoorg/files/news/magazine/ISOfocus\%20(2013NOW)/en/2020/ISOfocus_139/ISOfocus_139_en.pdf (дата обращения: 02.04.2020).

${ }^{7}$ ГОСТ Р 56020-2014 Бережливое производство. Основные положения и словарь.-М.: Стандартинформ, $2015 .-23$ с.
} 
управления успешно решаются на основе реализации требований ГОСТ Р 56404-2015 «Бережливое производство. Требования к системам менеджмента» ${ }^{8}$. В таблице 1 представлен результаты корреляции поставленных задач по совершенствованию качества работы клиентской службы и требований стандарта к системам менеджмента бережливого производства.

Связь задач совершенствования качества работы клиентской службы и требований стандартов к системам менеджмента бережливого производства

\begin{tabular}{|c|c|}
\hline $\begin{array}{c}\text { Задачи } \\
\text { совершенствования }\end{array}$ & ГОСТ Р 56404-2015 \\
\hline $\begin{array}{l}\text { Равномерное } \\
\text { распределение } \\
\text { нагрузки между } \\
\text { специалистами } \\
\text { клиентских служб }\end{array}$ & $\begin{array}{l}5.3 \text { Высшему руководству следует распределять ответственность и } \\
\text { полномочия таким образом, чтобы совершенствовать процессы организации } \\
\text { 10.2.3 Деятельность по улучшению следует направить на: выравнивание } \\
\text { потоков создания ценности; синхронизацию потоков создания ценности. }\end{array}$ \\
\hline $\begin{array}{l}\text { Внедрение } \\
\text { современных } \\
\text { программных } \\
\text { комплексов, } \\
\text { аккумулирующими } \\
\text { информационные } \\
\text { базы данных на } \\
\text { федеральном уровне }\end{array}$ & $\begin{array}{l}\text { 6.2.3 При постановке целей организации следует определить и использовать } \\
\text { методы развертывания целей по соответствующим функциям и уровням } \\
\text { организации. } \\
7.4 \text { Организации следует использовать каналы коммуникаций для } \\
\text { осуществления прямых и обратных связей как по вертикали (по уровням } \\
\text { управления), так и по горизонтали (по функциям). К каналам коммуникации } \\
\text { следует относить ... информационные системы и другие способы обмена } \\
\text { информацией. } \\
10.2 .3 \text { Деятельность по улучшению следует направить на: улучшение } \\
\text { характеристик информационного и материального потоков. }\end{array}$ \\
\hline $\begin{array}{l}\text { Оказание } \\
\text { населению } \\
\text { посредством } \\
\text { электронных } \\
\text { сервисов }\end{array}$ & $\begin{array}{l}\text { 8.3. Проектирование } \\
\text { В процессах проектирования следует применять: } \\
\text { г) специализированные информационные системы. } \\
\text { Организация должна планировать проектирование и разработку продукции и } \\
\text { процессов для выполнения требований к продукции и услугам с точки зрения } \\
\text { потребителя. } \\
\text { 10.2.2 Организации следует принимать меры по увеличению ценности для } \\
\text { потребителей на всех этапах операционной деятельности } \\
10.2 .3 \text { Деятельность по улучшению следует направить на: улучшение } \\
\text { характеристик финансового, информационного и материального потоков. }\end{array}$ \\
\hline
\end{tabular}

В данной работе мы рассмотрим задачу «Равномерное распределение нагрузки между специалистами клиентских служб» и подходы к её решению с помощью стандартов по бережливому производству: 1) ГОСТ Р 57524-2017 Бережливое производство. Поток создания ценности; 2) ГОСТ Р 56908-2016 Бережливое производство. Стандартизация работы; 3) ГОСТ Р 56907-2016 Бережливое производство. Визуализация; 4) ГОСТ Р 56906-2016 Бережливое

${ }^{8}$ ГОСТ Р 56404-2015 Бережливое производство. Требования к системам менеджмента.- М.: Стандартинформ, 2015.- $27 \mathrm{c}$. 
производство. Организация рабочего пространства. (5S); 5) ГОСТ Р 57523-2017 Бережливое производство. Руководство по системе подготовки персонала.

Организационно-методические подходы к решению данной задачи представлены нами в виде шести этапов каждый из которых сопровожден примерами применения рекомендаций.

Первый этап: картирование потока создания ценности (ГОСТ Р 57524-2017 $)$

Поток создания ценностей является практическим инструментом для определения структуры и продолжительности предоставляемых услуг населению клиентскими службами по всем направлениям деятельности с подсчетом трудозатрат по каждой услуги либо её операции. Перечень операций исключает непрофильные виды работ, которые не связанны с приемом и регистрацией заявлений, обращений и консультаций клиентов, и, как результат: полностью исключает несвойственные для клиентских служб операции; жестко регламентирует временные затраты на оказание услуг и выполнении операций; выравнивает нагрузку между специалистами как в рамках одной клиентской службы, так и между клиентскими службами края (независимо город или сельский район). Это первое средство поиска резерва для сокращения трудозатрат чистка операционной деятельности, установка временных ограничений трудозатрат.

\section{Пример:}

Расчет трудозатрат на выполнение услуг/операций клиентской службой (формула 1):

$$
\begin{aligned}
& \text { Кол - во оказанных услуг } \times \\
& \frac{\text { Норматив раб. времени для услуги }}{60 \text { мин. }}=\text { Факт. трудозатраты } \frac{\text { чел }}{\text { час }}
\end{aligned}
$$

Расчет потребности трудовых ресурсов (чел) для выполнения операций клиентских служб, если количество рабочих дней в году - 247 дней; количество рабочих дней в году специалиста клиентской службы - 221 день; продолжительность рабочего дня 8 часов (формула 2):

Трудозатраты/Продолж - ть раб. дня/Кол - во раб.дней в году = Потребность (чел.)

\section{Второй этап: стандартизация оказания услуг (ГОСТ Р 56908-2016 ${ }^{10}$ )}

Цель внедрения стандартизации: единая стандартизация действий специалистов при оказании услуг населению; возможность оперативного включения в процесс приема сотрудников другой специализации (важно в пиковые нагрузки; при нахождении в отпусках и больничных); объединение в одном технологическом документе - нормативных и инструктивных рекомендаций - База знаний для клиентских служб; оперативное реагирование на нормативные, инструктивные, технологические и технические изменения.

Структура порядка действий оказания услуг клиентскими службами: схема оказания услуги (обращение гражданина от цикла приема до конечного результата); описание приема граждан в единообразном стиле и структуре для всех стандартов (общая информация об услуге; способ подачи заявлений и документов (действующий); необходимые документы, которые

\footnotetext{
${ }^{9}$ ГОСТ Р 57524-2017 Бережливое производство. Поток создания ценности.- М.: Стандартинформ, $2017 .-27$ с.

${ }^{10}$ ГОСТ Р 56908-2016 Бережливое производство. Стандартизация работы.- М.: Стандартинформ, $2016 .-14$ с.
} 
представляет заявитель; необходимые документы, которые заполняет и запрашивает специалист; действия специалиста в присутствии гражданина, в том числе с использованием персональных компьютеров; действия специалиста без участия гражданина; действия руководителя клиентской службы; действия при возникновении внештатных ситуаций; статус наличия возможности оценки качества предоставления услуг посредством информационноаналитической системы мониторинга качества государственных услуг. И как результат получаем второе средство поиска резерва для сокращения трудозатрат - исключение неэффективных, дублирующих, бесполезных операций. Неоспоримый эффект внедрения состоит еще и в том, что стандартизация позволяет вывести персонал клиентских служб на уровень универсального специалиста, способного оказать весь спектр услуг в зависимости от жизненной ситуации гражданина, а также от потребности в государственных услугах у населения на данном этапе.

Пример: обращение за услугой, на приеме специалист, который впервые оказывает эту услугу. При использовании специалистом порядка действий, клиент даже не почувствует, что эта услуга оказывается сотрудником впервые.

Tретий этап: визуализация (ГОСТ Р 56907-2016 ${ }^{11}$ )

Целью визуализации (визуального оформления клиентских служб) является прозрачность процесс создания ценности и клиентоориентированность как повышение информированности потребителей. Это позволяет быстро обнаруживать несоответствия, обеспечивать выполнение стандартов, прозрачность ролей и ответственности работников. Визуальное оформление клиентских служб обеспечивает единое информационное и визуальное оформление клиентских служб с учетом специфики зданий и размещения мест приема граждан в организации. Эффект от внедрения инструментов визуализации: повышение уровня информированности и качества обслуживания граждан; доступность услуг не зависимо от месторасположения и состава клиентских служб; оперативное реагирование на потребности населения в актуальной информации.

\section{Пример:}

Эффективность применения инструментов визуализации возможно рассчитать по формуле 3: где Эф визуализации - эффективность применения инструментов визуализации; $k^{\prime \prime+"}$ количество поступивших положительных отзывов и благодарностей от граждан.

$$
Э \phi_{\text {визуализации }}=\frac{\boldsymbol{k}^{\prime \prime+"}}{\text { общее кол-во консультаций }} * 100
$$

Четвертый этап: организация рабочего пространства (5S) (ГОСТ P 56906-2016 $\left.{ }^{12}\right)$

Совершенствование оснащенности зала ожидания и рабочих мест - учет наличия и потребности в материально - технических ресурсах клиентских служб или организация рабочего пространства, направленная на мотивацию и вовлечение персонала в процесс улучшения оказываемых услуг, процессов, системы менеджмента организации, снижение потерь, повышение безопасности и удобства в работе. Организация должна определить

\footnotetext{
${ }^{11}$ ГОСТ Р 56907-2016 Бережливое производство. Визуализация.- М.: Стандартинформ, 2016.- 9 с.

12 ГОСТ Р 56906-2016 Бережливое производство. Организация рабочего пространства. (5S).- М.: Стандартинформ, 2016.- 15 c.
} 
перечень нужных предметов, с указанием их наименования и количества, на каждом рабочем месте, рабочем пространстве. К нужным предметам относятся предметы, без которых невозможно осуществление трудовой деятельности на рабочем месте/пространстве. Организация рабочего пространства клиентской службы (оснащенность зала ожидания и рабочих мест) содержит все позиции, которые внесены в требования по материально техническому оснащению клиентских служб и их фактическое состояние. Первоначально осуществляется планирование бюджета с учетом потребности в дооснащении, модернизации, комплектации материально - техническими ресурсами клиентских служб и их фактическим исполнением. Далее осуществляется размещение нужных предметов на рабочем месте (рабочем пространстве) таким образом, чтобы максимально снизить потери при их использовании и поиске персоналом организации.

\section{Пример:}

Функционал клиентских служб охватывает весь спектр деятельности организации, в связи с чем на рабочем месте специалиста установлено более десятка программных комплексов. Каждый из комплексов необходим для оказания той или иной услуги. Для удобства и целевого использования программных комплексов внедрена $5 \mathrm{~S}$. Благодаря сортировки собрана информация о персональном компьютере (ПК); режимы доступа; форма заявки; ответственные сотрудники; информация о руководстве пользователя. Для реализации конкретной задачи специалист не тратит на поиск соответствующего программного обеспечения, а с помощью поиска по ключевому слову автоматически подключается к необходимой программе. Также исключается возможность использование другого ПК необозначенного в паспорте.

На этапе совершенствования периодически рассматриваются вопросы о целесообразности использования определенных ПК с учетом развития профильного программного обеспечения.

Пятый этап: обучение персонала (ГОСТ Р 57523-2017 ${ }^{13}$ )

Провайдер онлайн-обучения edu CBA сообщает, что организации, добившиеся успеха в 21-м веке, оценивают навыки своих сотрудников в $85 \%$ от общего объема активов ${ }^{14}$. Люди могут быть определены как «нематериальные активы» в том смысле, что их нелегко отразить в денежном выражении, например, посчитать процент вклада вовлеченного персонала в результаты организации и выразить долю активного содействия в совершенствовании системы менеджмента.

Обучение персонала - совершенствование процесса управления знаниями и обеспечение клиентских служб компетентным персоналом. Система подготовки персонала основывается на следующих принципах: целенаправленность (основные цели связаны с повышением удовлетворенности потребителя, а также с повышением эффективности и результативности процессов, т.е. с неизменным сокращением затрат); согласованность обучения инструментам «бережливости» с другими направлениями обучения (охрана труда, информационная грамотность и пр.); многоуровневость (охватывает персонал организации на всех уровнях управления) для формирования бережливого мышления, реализуется через каскадную форму подготовки (передачу знаний и навыков от прошедших подготовку работников другим

${ }^{13}$ ГОСТ Р 57523-2017 Бережливое производство. Руководство по системе подготовки персонала.- М.: Стандартинформ, 2017.- 28 с.

14 Lockett, K. Building success through people. ISO focus, 2020.- pp. $43-49 . \quad-\quad$ s. 43 URL.: https://www.iso.org/files/live/sites/isoorg/files/news/magazine/ISOfocus\%20(2013-

NOW)/en/2020/ISOfocus_139/ISOfocus_139_en.pdf (дата обращения: 02.04.2020). 
работникам и с учетом отведенной роли в работах по бережливому производству); сбалансированность теоретических знаний и практических навыков по бережливому производству; регулярность (предусматривает периодическую подготовку и переподготовку персонала) в области бережливого производства для поддержания необходимого уровня компетентности; вовлеченность высшего руководства в программах подготовки и демонстрацией повышения собственной компетентности, а также созданием среды для результативной подготовки персонала. Оценку результатов функционирования системы подготовки персонала в области бережливого производства возможно проводить через оценку результативности реализуемого сотрудником процесса.

\section{Пример:}

Авторами разработаны целевые показатели для оценки исполнителей процесса предоставления государственных услуг и подходы к оценке эффективности деятельности в работе «Оценка менеджмента качества системы социального обеспечения» [16]. На основе данных определяются: нагрузка по оказанию услуг; потребность в повышении уровня компетентности по отдельным направлениям деятельности клиентских служб; актуальные тематики для изучения; мастер - классы лучших практик; вопросы оказания практической помощи; вопросы психологической поддержки. Совершенствование процесса управления знаниями и повышение компетентности персонала осуществляется с учетом трудозатрат, рассчитанных на основании Потока создания ценностей и Стандартизации, и позволяет сократить дисбаланс нагрузки на специалистов и определить оптимальную численность специалистов клиентский служб. Данный подход позволит сформировать оптимальный кадровый состав клиентских служб с учетом направлений деятельности, численности специалистов и стандартизации выполняемых операций. Важным элементом является система мотиваций специалистов, к ней относится не только материальное стимулирование, но и меры морального воздействия. К последнему можно отнести Ежегодные конкурсы клиентских служб. Номинации конкурса: «Лучшая клиентская служба»; «Лучший руководитель клиентской службы»; «Лучший специалист клиентской службы».

\section{Выводы}

Стандартизация и механизм, обеспечивающий упреждающее развитие по отношению к динамике потребностей, позволяет создавать продуктивную инновационную среду для внедрения бережливого производства. Область применения организационно-методических подходов инновационного обеспечения качества управления клиентской службой может быть распространена на другие территориальные органов социального обеспечения РФ, а также прочие службы системы государственного управления. Представленные результаты являются новыми для системы социального обеспечения ввиду отсутствия данного опыта применения требований к системам менеджмента бережливого производства.

Основные результаты: с помощью картирования потоков создания ценности операционной деятельности найдены резервы для сокращения трудозатрат специалистов клиентской службы. На основе стандартизации работ персоналу клиентской службы определена роль универсального специалиста, способного оказать весь спектр услуг в зависимости от жизненной ситуации гражданина. Применение инструментов визуализации позволило повысить уровень информированности, качества обслуживания граждан и доступности услуг не зависимо от месторасположения и состава клиентских служб, а также снизить нагрузку на специалистовконсультантов. Организация рабочего пространства клиентской службы по системе $5 \mathrm{~S}$ позволила снизить потери при операционной деятельности и рациональные организовать 
материальные и информационные потоки. С помощью Руководства по обучению персонала разработан план по повышению компетентности персонала клиентских служб в области бережливого производства.

Таким образом, требования к системам менеджмента бережливого производства и существующие инструменты бережливого производства позволяют рассматривать механизмы стандартизации как инновационное обеспечение качества управления системы государственного управления на всех её уровнях, для всех процессов и операций клиентской службы. Предложенные организационно-методические подходы могут быть применены для системы государственного управления и прочих сложных хозяйствующих субъектов с целью повышения: удовлетворенности потребителей и других заинтересованных сторон; результативности и эффективности бизнес-процессов, процессов менеджмента, обеспечивающих процессов для быстрого и гибкого реагирования на изменения внешней среды. Т.е. результаты формирования инновационной среды будут отражаться в результатах процессов организации, которые с одной стороны будут повышать производительность труда и качество предоставления услуг, с другой стороны снижать затраты на качество.

\section{Литература:}

1. Артюхина С.В., Панкина Г.В., Соляник А.И. Совершенствование механизмов инновационного обеспечения управления качеством в региональных системах среднего профессионального образования. Монография. - Москва, 2014. - 105 с. URL: https://search.rsl.ru/ru/record/01006763354

2. Герасимова Г.А., Жариков В.Д. Инновационное обеспечение повышения качества продукции // Вопросы современной науки и практики. Университет им. В.И. Вернадского. 2014. - № 1 (50). - C. 165-170. URL: https://elibrary.ru/item.asp?id=21301916

3. Дмитриев М.Э., Крапиль В.Б., Маслов Д.В. Может ли государство стать бережливым? // Стандарты и качество. - 2020. - № 2. - С. 66-70. URL: https://www.elibrary.ru/item.asp?id=42313620

4. Дмитриев М.Э., Золотарева А.Б., Крапиль В.Б. Направления оптимизации административных процессов (на примере службы занятости) // Вопросы государственного и муниципального управления. - 2018. - № 1. - $\mathrm{C}$. https://elibrary.ru/item.asp?id=32697813

5. Дмитриев М.Э., Крапиль В.Б. Ожидания и реальность оптимизации административных процессов: «быстрые победы» или «долгая дорога в гору»? // Общественные науки и современность. - 2017. - № 5. - С. 5-17. URL: https://elibrary.ru/item.asp?id=29953749

6. Едаменко Е.А., Панибратец Е.Ю., Чукавов Е.С. Бережливые технологии как перспектива совершенствования государственного и муниципального управления // Экономика. Менеджмент. Инновации. - 2018. - № 3 (15). - C. 19-26. URL: https://elibrary.ru/item.asp?id=38596782

7. Жариков Р.В. Процессный подход к инновационному обеспечению управления качеством машиностроительной продукции // Организатор производства .- 2011. -№ 1 (48). - С. 85-88. URL: https://elibrary.ru/item.asp?id=15516639

8. Жариков Р.В. Эволюция развития инновационного обеспечения управления качеством машиностроительной продукции //Актуальные инновационные исследования: наука и практика. - 2011. - № 2. - C. 11. URL: https://elibrary.ru/item.asp?id=16948769 
9. Левшина В.В., Трошкова Е.В. Система менеджмента качества: инновационный проект: монография. - Новосибирск: Изд. АНС «СибАК», 2017. - 160 с. URL: https://elibrary.ru/item.asp?id=30467711

10. Лапидус В.А., Олухов А.Е. Интегрированная система менеджмента качества и бережливого производства // Стандарты и качество. - 2017. - №6. - С. 50-54. URL: https://elibrary.ru/item.asp?id=29313635

11. Леонидов К., Никитин Г., Лапидус В., Олухов А. Стандарты серии «Бережливое производство»: управление эффективностью деятельности // Стандарты и качество. - 2017. №6. - C. 46-49. URL: https://elibrary.ru/item.asp?id=29313634

12. Марков Д.А. Бережливое и быстрореагирующее производство: монография.-Минво образования и науки РФ, ФГБОУ ВО «Пермский национальный исследовательский политехнический университет». - Пермь : Изд-во Пермского нац. исслед. политехнического унта, 2018. - 324 с. URL: https://search.rsl.ru/ru/record/01009631089

13. Матвеева К.В. Разработка методов и алгоритмов инновационного обеспечения управления качеством: автореферат диссертации ... кандидата экономических наук: 08.00.05; [Место защиты: Иркут. гос. техн. ун-т]. - Иркутск, 2010. - 179 с. URL: https://dlib.rsl.ru/viewer/01004615603\#?page=1

14. Мкртчян T.P. Инновационное обеспечение управления качеством на предприятии: монография. - СПб.: ФГБОУВО «СПбГУПТД», 2018. -109 с. URL: https://elibrary.ru/item.asp?id=37186981

15. Обухова С.Н., Карасёва М.В., Трошкова Е.В. Оценка менеджмента качества системы социального обеспечения // Вестник алтайской академии экономики и права. - 2019. №11. - C. 129-136. URL: https://elibrary.ru/item.asp?id=41474396

16. Плетнева Т.В. Роль Лин-технологий в проактивном управлении знаниями // Научные вести. - 2018. - № 3. - С. 62-66. URL: https://www.elibrary.ru/item.asp?id=36655695

17. Савицкая И.М., Горбанев С.В., Андреева И.В. Реализация концепции «бережливое производство» в сфере оказания государственных и муниципальных услуг // Новые технологии. - 2018. - № 2. - С. 85-93. URL: https://elibrary.ru/item.asp?id=36655695

18. Саликов Ю.А., Каблашова И.В. Совершенствование организации процессов производства в условиях инновационного развития системы менеджмента качества // Вестник Воронежского государственного университета инженерных технологий. - 2016. - № 4 (70). - С. 488-498. DOI: 10.20914/2310-1202-2016-4-488-498 URL: https://elibrary.ru/item.asp?id=28340852

19. Сиббет Д. Увидеть решение: визуальные методы управления бизнесом /Д. Сиббет; Пер. с анг. - М.: Альпина Паблишер, 2016.-256 с.

20. Царенко А.С. «Бережливое государство»: перспективы применения бережливых технологий в государственном управлении в России и за рубежом // Государственное управление. Электронный вестник. - 2014. - № 45. - C. 74-109.- URL: https://elibrary.ru/item.asp?id=22015348

21. Царенко А. С., Гусельникова О.Ю. Проекты «бережливый регион», «бережливая поликлиника», «бережливый город» как шаги на пути к созданию «бережливого правительства»: оценка реализации лин-инициатив в государственном секторе РФ // Государственное управление. Электронный вестник. - 2019. - №73. - С. 167-203. URL: https://elibrary.ru/item.asp?id=37534137 
22. Чайка И.И. Стандартизация и оценка соответствия в сфере бережливого производства // Сертификация. - 2015. - №4. - C. 5-8. URL: https://elibrary.ru/item.asp?id=25340762

23. Шулешко, А.Н. Принципы, методология и инструменты инновационного обеспечения управления качеством: диссертация ... доктора экономических наук: 08.00.05; [Место защиты: Иркутский государственный технический университет]. - Иркутск, 2012. - 304 c. URL: https://search.rsl.ru/ru/record/01005012000

24. Ястребова М.В. Управление инновационным обеспечением повышения качества медицинских услуг и эффективности деятельности системы здравоохранения: диссертация ... кандидата экономических наук : 08.00.05; [Место защиты: С.-Петерб. акад. упр. и экономики]. Санкт-Петербург, 2011. - 155 c. URL: https://search.rsl.ru/ru/record/0100484119325

25. Hosley, William N. Innovative approaches to quality assurance in project management / Proceedings of the Project Management Institute Annual Seminar Symposium, 1984. - pp. 201-211. URL: https://www.scopus.com/Hosley

\section{References:}

1. Artyukhina S.V., Pankina G.V., Solyanik A.I. Improving the mechanisms of innovative quality management in regional systems of secondary vocational education. Moscow, 2014, 105 p. . (In Russian) URL: https://search.rsl.ru/ru/record/01006763354

2. Gerasimova G.A., ZHarikov V.D. Innovative support for improving product quality. Questions of modern science and practice. University named after IN AND. Vernadsky, 2014, no. 1 (50), pp. 165-170. (In Russian) URL: https://elibrary.ru/item.asp?id=21301916

3. Dmitriev M.E., Krapil V.B., Maslov D.V. Can the state become thrifty? Standards and quality, 2020, no. 2, pp. 66-70. (In Russian) URL: https://www.elibrary.ru/item.asp?id=42313620

4. Dmitriev M.E., Zolotareva A.B., Krapil' V.B. Directions of optimization of administrative processes (for example, the employment service). Issues of state and municipal administration, 2018, no. 1, pp. 7-28. (In Russian) URL: https://elibrary.ru/item.asp?id=32697813

5. Dmitriev M.E., Krapil' V.B. Expectations and reality of streamlining administrative processes: "quick victories" or "long road uphill”? Social Sciences and the Present, 2017, no. 5, pp. 517. (In Russian) URL: https://elibrary.ru/item.asp?id=29953749

6. Edamenko E.A., Panibratets E.Yu., Chukavov E.S. Lean technologies as the prospect of improving state and municipal management. Economics. Management. Innovation, 2018, no. 3 (15), pp. 19-26. (In Russian) URL: https://elibrary.ru/item.asp?id=38596782

7. Zharikov R.V. The process approach to innovative quality management of engineering products. Production Organizer, 2011, no 1 (48), pp. 85-88. (In Russian) URL: https://elibrary.ru/item.asp?id=15516639

8. ZHarikov R.V. The evolution of the development of innovative quality management of engineering products. Actual innovative research: science and practice, 2011, no. 2, pp. 11. (In Russian) URL: https://elibrary.ru/item.asp?id=16948769

9. Levshina, V.V., Troshkova E.V. Quality management system: innovation project. Novosibirsk, "SibAK" Publ., 2017, 160 p. URL: https://elibrary.ru/item.asp?id=30467711

10. Lapidus V.A., Olukhov A.E. Integrated quality management system and lean manufacturing. Standards and quality, 2017, no. 6, pp. 50-54. (In Russian) URL: https://elibrary.ru/item.asp?id=29313635 
11. Leonidov K., Nikitin G., Lapidus V., Olukhov A. Standards of the Lean Production series: performance management. Standards and quality, 2017, no. 6, pp. 46-49. URL: https://elibrary.ru/item.asp?id=29313634

12. Markov, D. A. Lean and responsive production. Perm Publ., 2018. 324 p. (In Russian). URL.: https://search.rsl.ru/ru/record/01009631089

13. Matveeva K.V. Development of methods and algorithms of innovative quality management support, Irkutsk, 2010, 179 p. URL.: https://dlib.rsl.ru/viewer/01004615603\#?page=1

14. Mkrtchyan, T.R. Innovative quality management at the enterprise. Saint Petersburg, FGBOUVO SPbGUPTD Publ., 2018, 109 p. (In Russian). URL: https://elibrary.ru/item.asp?id=37186981

15. Obukhova, S.N., Karaseva, M.V., Troshkova E.V. Assessment of quality management of the social security system. Bulletin of the Altai Academy of Economics and Law, 2019, no 11, pp. 129-136. (In Russian) URL: https://elibrary.ru/item.asp?id=41474396

16. Pletneva T.V. The role of Lin-technologies in proactive knowledge management. Scientific News, 2018, no. 3, pp. 62-66. (In Russian) URL.: https://www.elibrary.ru/item.asp?id=36655695

17. Savitskaya I.M., Gorbanev S.V.,Andreeva I.V. Implementation of the concept of "lean manufacturing" in the provision of state and municipal services. New Technologies, 2018, no. 2. pp. 85-93. (In Russian) URL: https://elibrary.ru/item.asp?id=36655695

18. Salikov Yu.A., Kablashova I.V. Improving the organization of production processes under the innovative development of a quality management system. Bulletin of the Voronezh State University of Engineering Technologies, 2016, no. 4 (70), pp. 488-498. (In Russian) DOI: 10.20914/2310-1202-2016-4-488-498 URL: https://elibrary.ru/item.asp?id=28340852

19. Sibbet D. See the solution: visual methods of business management), Moscow, Al'pina Publ., 2016, 256 p.

20. Carenko A.S. «Lean state» prospects for the application of lean technologies in public administration in Russia and abroad. Public Administration. Electronic bulletin, 2014, no. 45, pp. $74-$ 109. (In Russian) URL: https://elibrary.ru/item.asp?id=22015348

21. Carenko A. S., Gusel'nikova O.Yu. Projects "Lean Region", "Lean Polyclinic", "Lean City" as Steps Towards the Creation of a "Lean Government": Evaluation of the Implementation of Lin-Initiatives in the Public Sector of the Russian Federation. Public Administration. Electronic Bulletin, 2019, no. 73, pp. 167-203. (In Russian). URL: https://elibrary.ru/item.asp?id=37534137

22. CHajka I.I. Standardization and conformity assessment in the field of lean manufacturing. Certification, 2015, no. 4, pp. 5-8. (In Russian) URL: https://elibrary.ru/item.asp?id=25340762

23. Shuleshko, A.N. Principles, methodology and tools of innovative quality management support. Irkutsk, 2012., $304 \mathrm{p}$.

24. Yastrebova M.V. Management of innovative support for improving the quality of medical services and the effectiveness of the health care system. St. Petersburg, 2011, $155 \mathrm{p}$.

25. Hosley, William N. Innovative approaches to quality assurance in project management. USA, Project Management Inst, Drexel Hill,PA Publ., 984, pp. 201-211. URL: https://www.scopus.com/Hosley

Submitted: 2 March 2020

Accepted: 10 April 2020

Published: 16 April 2020

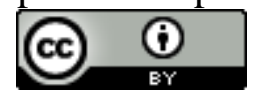

